\title{
Mosquito communities and disease risk influenced by land use change and seasonality in the Australian tropics
}

\author{
Dagmar B. Meyer Steiger ${ }^{1 *}$, Scott A. Ritchie ${ }^{2}$ and Susan G. W. Laurance
}

\begin{abstract}
Background: Anthropogenic land use changes have contributed considerably to the rise of emerging and re-emerging mosquito-borne diseases. These diseases appear to be increasing as a result of the novel juxtapositions of habitats and species that can result in new interchanges of vectors, diseases and hosts. We studied whether the mosquito community structure varied between habitats and seasons and whether known disease vectors displayed habitat preferences in tropical Australia.

Methods: Using CDC model 512 traps, adult mosquitoes were sampled across an anthropogenic disturbance gradient of grassland, rainforest edge and rainforest interior habitats, in both the wet and dry seasons. Nonmetric multidimensional scaling (NMS) ordinations were applied to examine major gradients in the composition of mosquito and vector communities.

Results: We captured $\sim 13,000$ mosquitoes from 288 trap nights across four study sites. A community analysis identified 29 species from 7 genera. Even though mosquito abundance and richness were similar between the three habitats, the community composition varied significantly in response to habitat type. The mosquito community in rainforest interiors was distinctly different to the community in grasslands, whereas forest edges acted as an ecotone with shared communities from both forest interiors and grasslands. We found two community patterns that will influence disease risk at out study sites, first, that disease vectoring mosquito species occurred all year round. Secondly, that anthropogenic grasslands adjacent to rainforests may increase the probability of novel disease transmission through changes to the vector community on rainforest edges, as most disease transmitting species predominantly occurred in grasslands.
\end{abstract}

Conclusion: Our results indicate that the strong influence of anthropogenic land use change on mosquito communities could have potential implications for pathogen transmission to humans and wildlife.

Keywords: Edge effects, Deforestation, Land use change, Mosquito community, Rainforest disturbance

\section{Background}

The emergence and re-emergence of mosquito-borne diseases can often be linked to human land use changes such as deforestation, agriculture and urbanization [1-5]. These land use changes may influence disease prevalence and distribution by increasing breeding habitats, food resources, and changing vector-host relationships [4, 6-8]. Tropical deforested habitats are open, well lit and warmer

\footnotetext{
* Correspondence: dagmar.meyersteiger@my.jcu.edu.au

${ }^{1}$ Centre for Tropical Environmental and Sustainability Studies (TESS) and College of Marine and Environmental Sciences, James Cook University, 4870 Cairns, Queensland, Australia

Full list of author information is available at the end of the article
}

compared to secondary and primary forests [9]. These characteristics may increase the survival and growth rates of mosquito larvae $[4,8,10,11]$. Newly available habitats for mosquitoes, such as irrigation systems, dams and other water-holding bodies, have also enabled mosquitoes to spread into previously uninhabitable areas [12,13].

A principle risk factor in the emergence of zoonotic diseases (diseases that transfer from other animals to humans) is the alteration of the vector-host relationship due to land use modification $[14,15]$. This change in relationship occurs when a vector is introduced to a new habitat or exposed to a new host. Human infection with 
yellow fever virus in South America is one such example $[16,17]$. Within their natural environment, the yellow fever virus (Flavivirus spp.) is mainly transmitted by Hemagogus, Sabethes and Aedes mosquitoes to monkeys in the rainforest canopy. After logging and land clearing, mosquitoes followed the canopy edge to the ground where they fed and infected humans [16-18].

Seasonality in the tropics can influence mosquito populations, as the duration of wet and dry seasons affects larval development and adult abundance. Wet season rains create more breeding habitats, and elevated humidity levels extend the lifespan of adults, thus prolonging disease transmission rates [3]. For example, dengue outbreaks regularly coincide with wet seasons in Brazil, Thailand and Australia [19-21].

Mosquito-borne diseases such as malaria, yellow fever and chikungunya are thriving worldwide, especially in the tropics. The tropical regions of Australia could also be vulnerable to these diseases as potential vectors are present and disease transmission could arise due to infected people entering the country [22-24]. For example, potential vectors that occur in tropical Australia are: Anopheles farauti and An. annulipes for spreading malaria [25], and Aedes aegypti for the transmission of yellow fever and chikungunya [26, 27]. Unfortunately, human populations in Australia's tropical regions are not immune to the effects of mosquito-borne infections as attested by outbreaks of dengue, Ross River fever, Barmah Forest virus, Japanese encephalitis and Murray Valley encephalitis virus [28]. There is very little known about the ecology of these diseases or their vectors in the Australian tropics and if environmental change has influenced their prevalence.

Our study investigated the mosquito community structure and composition across an anthropogenic disturbance gradient of grassland, forest edge and forest interior habitats in the tropical lowlands of north Queensland, Australia. Our main objectives were to evaluate how mosquito abundance, number of species and species composition differed between the three habitat types and across seasons. Our study presents a template to assess how landscape disturbances are able to influence mosquito species composition and distribution in the tropics and how those changes may influence mosquito borne diseases.

\section{Methods}

\section{Study area}

This study was conducted in the Wet Tropics bioregion of north eastern Australia. Study sites were located approximately 10 to $15 \mathrm{~km}$ north of Cairns city, $\left(16^{\circ}\right.$ $50^{\prime}$ S, $145^{\circ} 41^{\prime} \mathrm{E}$ (Fig. 1), which provides an ideal setting for the analysis of mosquito response to land use changes as Cairns' human population is growing and

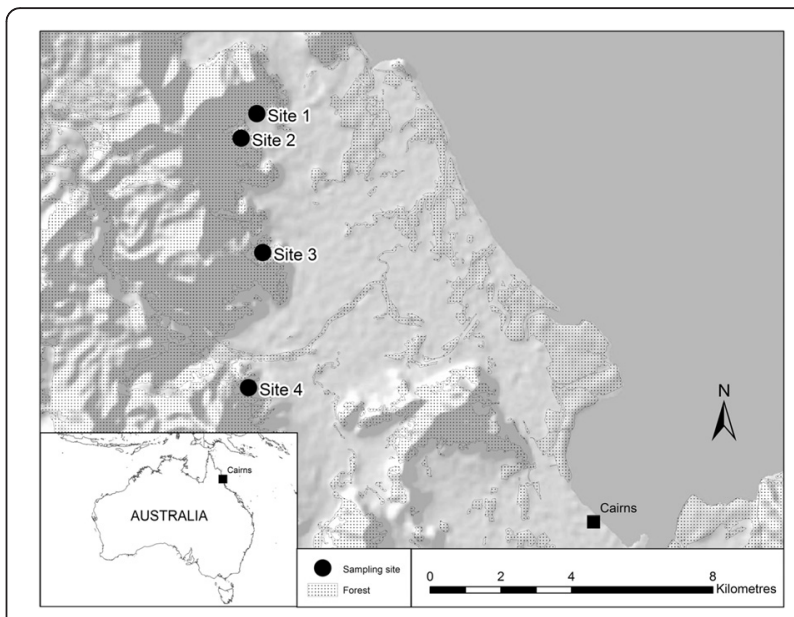

Fig. 1 Map of study area and sampling sites. The study area, north of Cairns, Australia showing the four sampling sites which feature similar ecological habitats and environmental gradients

urban areas are expanding into agricultural and forest habitats. The population has more than doubled within 25 years (1981-2006) from 70,762 to 147,538. Furthermore, it is expected to be 1.4 to 1.7 times larger by 2031 [29], resulting in further land use changes [30]. Cairns is also an important tourist destination with an international airport and seaport for cruise liners and container ships; all of which have the potential to introduce exotic infectious agents into the country [31-34].

Annual rainfall is ca. $2000 \mathrm{~mm} \mathrm{yr}^{1}$ and strongly seasonal with a wet season from December to May and a dry season from June to November. Temperature reaches an annual mean maximum and minimum of $29{ }^{\circ} \mathrm{C} \mathrm{yr}{ }^{1}$ and $20.8{ }^{\circ} \mathrm{C} \mathrm{yr}{ }^{1}$ respectively. The lowland evergreen rainforests within the study area are classified locally as Notophyll Vine Forests (Type 7) [35]. These forests contain trees that are $15-24 \mathrm{~m}$ in height with emergents such as Acacia polystachya, Eucalytpus pellita and Eucalyptus tessellaris on the ridges [35]. The forests have had some anthropogenic disturbances such as the removal of timber species [36], and fires that have escaped from cane farms [37]. The grasslands surrounding the forests were man-made and dominated by 2 $4 \mathrm{~m}$ high non-native grasses, shrub species, and some pioneer rainforest trees.

\section{Sampling methods for mosquitoes}

Field work was conducted between October 2011 and August 2012 at four sites with similar ecological habitats and environmental gradients. Every site was sampled four times; twice in the wet season and twice in the dry season. We captured adult mosquitoes from three different habitats: forest interior, forest edge and adjacent grassland. The distance between each of these habitats was at least 100 meters. Mosquitoes were collected using 
Center for Disease Control and Prevention (CDC) light traps (model 512, John W. Hock Company, Gainesville, Florida). The traps were modified by removing the light bulbs to avoid sample bias - as some mosquito species may be more attracted to light than others; to reduce attracting non-target insects that can damage mosquitoes; and to increase battery life [38]. All traps were run with 6 volt batteries. Six traps were set up in each habitat at each site resulting in 18 trap catches per site per sampling period. Traps were established along a transect at least 20 meters apart and were placed at a height of approximately 1.5 meters above ground level. The traps were baited with $\mathrm{CO}_{2}$ (2 kg dry ice per trap) in insulated containers, which were placed directly above the traps. Vaseline petroleum jelly was applied to suspension ropes to deter green ants (Oecophylla smaragdina) from reaching the caught mosquitoes. Traps were in operation for $24 \mathrm{~h}$ to ensure that both diurnal and nocturnal mosquito species were captured. After collecting the traps, species were stored in the insulated containers on the remaining dry ice and taken back to the laboratory where they were placed into freezers $\left(-21^{\circ} \mathrm{C}\right)$ for further storage.

\section{Mosquito identification}

Mosquitoes were identified to species level using taxonomic keys $[25,39,40]$ and with the assistance of taxonomic experts. The identification of mosquitoes is time consuming as it generally requires the keying out of each individual. Due to the large numbers of mosquitoes captured we applied a subsampling procedure that required the random selection of individuals for identification, this method was previously tested [41] and was found to accurately predict species diversity and maintain species proportions within the community.

\section{Statistical analysis}

We assessed whether the subsampling technique accurately described species composition by comparing the relative abundance of one species (Coquillettidia nr.crassipes) in the subset with its actual abundance in the whole sample, by using Spearman's rank order correlation. Only traps that had captured $\geq 80$ mosquitoes were used which resulted in 30 traps being analysed. We only included traps with $\geq 80$ mosquito captures due to the results of our pilot study which showed that cumulative species richness begins to plateau at 80 individuals.

We estimated the differences in mean abundance for each habitat type (forest interior, forest edge and grassland) and each season (wet and dry season) using a twoway ANOVA (independent factorial design with fixed factors). Variables were log-transformed to satisfy the assumptions of the residuals conforming to a normal distribution and in homogeneity of variances. A two-way ANOVA was also used to assess whether there was a difference in mean number of species between habitats and seasons. Data were not transformed prior to the analysis as statistical assumptions were met. The data for the early and late dry seasons, and the early and late wet season were pooled to derive the dry season and wet season data respectively. Rank-abundance diagrams distinguished changes in species dominance between habitats and seasons.

To evaluate if mosquitoes were sampled adequately under our sampling design, we constructed a species accumulation curve to display the cumulative number of species collected against the measure of sampling effort. The sampling effort is all data across the three habitats. Chi-square tests were applied to investigate whether the different mosquito tribes and subfamilies had habitat preferences.

To examine major gradients in the composition of mosquito communities and vector communities (vector communities consist of species which are able to transmit alpha-, flaviviruses and protozoans) between habitat types and seasons, we performed nonmetric multidimensional scaling (NMS) ordinations. Data were $\log (n+1)$ transformed prior to analysis. Monte Carlo randomization tests (250 runs) were used to determine whether the ordination axes explained significantly more variation than expected by chance. A Bonferroni correction was used to reduce the likelihood of type II errors, where $P=0.15 / \mathrm{x}$ (x represents the number of mosquito species multiplied by two or three axes and 0.15 is the experiment wise error rate) [42]. Permutation-based nonparametric MANOVAs (PerMANOVAs) [43], followed by pairwise comparisons for significant results, were employed to distinguish differences in mosquito communities for the three habitat types.

Finally, we assessed whether there were differences between commonly captured mosquitoes ( $>40$ individuals) with similar ecological and biological characteristics by applying two-way ANOVA tests. Species were grouped according to the following three ecological and biological characteristics: geographical range in Australia, breeding environments and time of blood-feeding with the use of published life history and distributional data $[25,40]$. The geographical range of species occurrence was divided into four groups: very restricted (species restricted to north Queensland only); restricted (species restricted to either north Queensland and Northern Territories or to Queensland and New South Wales); medium (northern Australia: Queensland, Northern Territories and Western Australia) and wide (all of Australia, except Tasmania). Mosquito species were further classified as using the following known breeding environments: ground water and containers (natural and artificial). Preferred time of blood-feeding of species was divided into diurnal, nocturnal and crepuscular (dawn and 


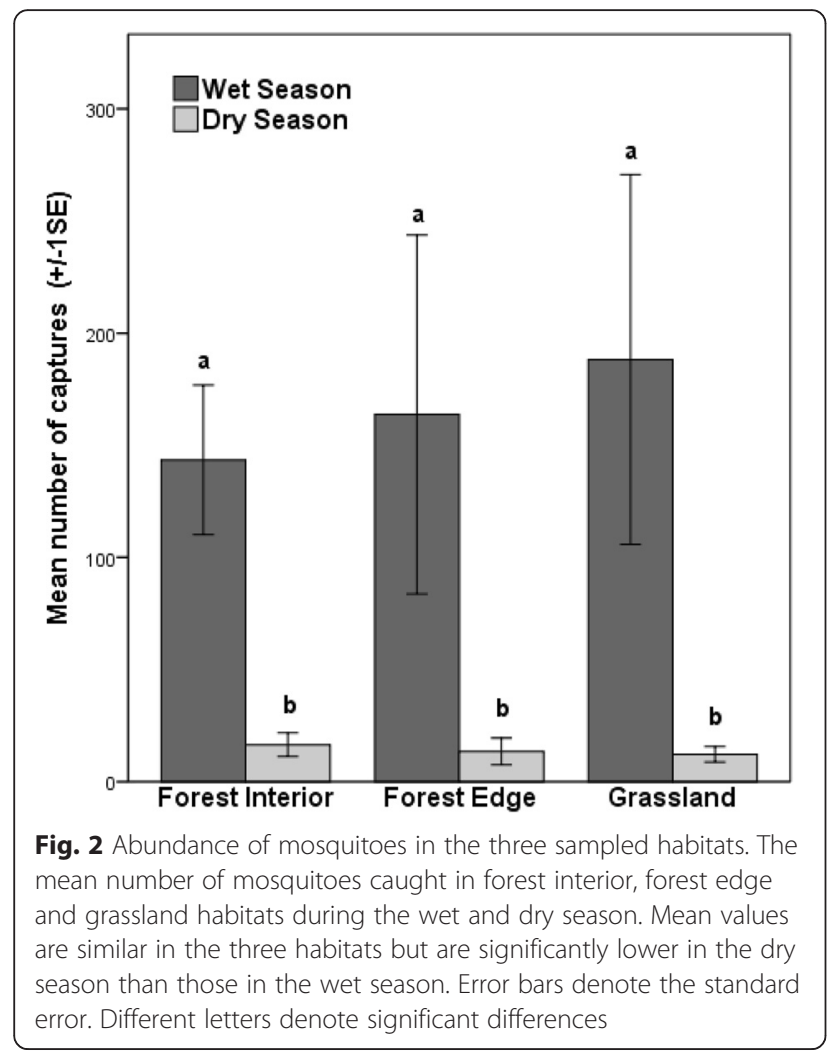

dusk). Geographical range data were square-root transformed to fulfill the assumptions of two-way ANOVAs.

We used SPSS statistical package (SPSS Statistics for Windows 22.0, Armonk, New York, USA) for most analyses, except for the ordination analyses and the PerMANOVAs for which we used PC-ORD (PC-ORD 6.0, MjM Software, Gleneden Beach, Oregon, USA). Where required, data was tested for normality by using the Kolmogorov-Smirnov tests and Levene's tests for homogeneity of variances.

\section{Results}

At the outset, we verified the accuracy of our subsampling method for estimating the relative abundance (proportion) of mosquito species. We found a strong positive correlation between the estimated and actual abundance of Cq.nr. crassipes in our samples (Spearman Rank Correlation $r_{\mathrm{s}}=$ 0.833, $P<0.001$ ), which infers that our subsampling technique adequately estimated species composition.

\section{Mosquito captures}

In total, 12,854 mosquitoes were captured in 288 trapnights across 16 grassland-edge-rainforest gradients. On average $93 \pm 86$ (mean \pm SD) mosquitoes were captured per trap (Additional file 1: Table S1). Mosquito captures were quite evenly distributed across the three habitats as there was no significant difference between the mean captures per habitat (2-way ANOVA $F_{(2,18)}=0.109, P=0.897$ ). However, seasonality influenced mosquito abundance strongly. Thirteen times more mosquitoes were captured during the wet season than during the dry season sampling period (2way ANOVA $F_{(1,18)}=65.555, P<0.0001$ ) (Fig. 2). No effect of interaction occurred between habitat and season (2-way ANOVA $\left.F_{(2,18)}=0.150, P=0.861\right)$.

We identified four tribes and two subfamilies of mosquitoes (Table 1) in the community. Members of the mosquito tribes Aedini and Mansoniini were found mostly in forest interior habitats $\left(\chi^{2}=186.39, d f=1, P<0.001\right.$ and $X^{2}=30.26, d f=1, P<0.001$ ), whereas members of the tribe Culicini were predominantly captured in grassland habitats $\left(\chi^{2}=92.57, d f=1, P<0.001\right)$. No habitat preference was found for the Sabethini tribe $\left(\chi^{2}=2.46, d f=1, P>\right.$ 0.05). Most (95\%) individuals were in the subfamily Culicinae, with only $5 \%$ in Anophelinae. Mosquitoes in the subfamily Culicinae were mostly captured inside forests $\left(x^{2}=21.84, d f=1, P<0.001\right)$ compared to mosquitoes in the subfamily Anophelinae which appeared to prefer open habitats, as they were significantly more abundant in grasslands compared to forest edges and forest interiors $\left(\chi^{2}=75.20, d f=1, P<0.001\right)$.

\section{Species richness}

The mosquito community was very diverse with 29 species (27 species in the wet season and 24 species in the dry season) identified from 7 genera (Table 2; Additional file 1:

Table 1 Mosquito abundance by tribe and subfamily from the three habitats in tropical Australia

\begin{tabular}{|c|c|c|c|c|c|c|c|c|c|c|c|}
\hline \multirow{2}{*}{\multicolumn{2}{|c|}{ Tribe/SUBFAMILY }} & \multicolumn{2}{|c|}{ Forest interior } & \multicolumn{2}{|c|}{ Forest edge } & \multicolumn{2}{|c|}{ Grassland } & \multicolumn{2}{|l|}{ Total } & \multicolumn{2}{|c|}{ Chi-Square test $(d f=2)$} \\
\hline & & $n$ & $\%$ & $n$ & $\%$ & $\mathrm{n}$ & $\%$ & $\bar{N}$ & $\%$ & $\overline{x^{2}}$ & $P$ \\
\hline \multicolumn{2}{|l|}{ Aedini } & 953 & 60.66 & 689 & 47.03 & 444 & 31.11 & 2086 & 46.74 & 186.39 & $<0.001$ \\
\hline \multicolumn{2}{|l|}{ Culicini } & 479 & 30.49 & 633 & 43.2 & 824 & 57.75 & 1936 & 43.38 & 92.57 & $<0.001$ \\
\hline \multicolumn{2}{|l|}{ Mansoniini } & 106 & 6.75 & 63 & 4.3 & 42 & 2.94 & 211 & 4.73 & 30.26 & $<0.001$ \\
\hline \multirow[t]{3}{*}{ Sabethini } & & 17 & 1.08 & 9 & 0.62 & 0 & 0 & 26 & 0.58 & 2.46 & $\mathrm{~ns}^{*}$ \\
\hline & Anophelinae & 16 & 1.02 & 71 & 4.85 & 117 & 8.2 & 204 & 4.57 & 75.2 & $<0.001$ \\
\hline & Culicinae & 1555 & 98.98 & 1394 & 95.15 & 1310 & 91.8 & 4259 & 95.43 & 21.84 & $<0.001$ \\
\hline
\end{tabular}

${ }^{*} n s$, not significant $(d f=1)$ 
Table 2 Total number of each mosquito species collected from each habitat ( $F$ = forest interior, $F E=$ forest edge, $G R=$ grassland) in north Queensland and the pathogens they may transmit

\begin{tabular}{|c|c|c|c|c|c|c|c|c|c|}
\hline \multirow[b]{2}{*}{ Species } & \multicolumn{4}{|c|}{ Wet Season } & \multicolumn{4}{|c|}{ Dry Season } & \multirow[b]{2}{*}{ Grand-tota } \\
\hline & $\mathrm{FI}$ & $\mathrm{FE}$ & GR & Total & $\mathrm{FI}$ & $\mathrm{FE}$ & GR & Total & \\
\hline Aedes alboscutellatus ${ }^{[?]}$ & 10 & 7 & 14 & 31 & 24 & 12 & 0 & 36 & 67 \\
\hline Aedes alternans ${ }^{[a]}$ & 1 & 5 & 4 & 10 & 0 & 0 & 0 & 0 & 10 \\
\hline Aedes kochi $i^{[a, d, e]}$ & 2 & 30 & 26 & 58 & 3 & 3 & 8 & 14 & 72 \\
\hline Aedes lineatopennis $[\mathrm{a}, \mathrm{g}]$ & 1 & 4 & 55 & 60 & 0 & 1 & 0 & 1 & 61 \\
\hline Aedes notoscriptus ${ }^{[a, b, d]}$ & 144 & 119 & 32 & 295 & 97 & 62 & 34 & 193 & 488 \\
\hline Aedes palmarum [?] & 15 & 2 & 0 & 17 & 24 & 7 & 1 & 32 & 49 \\
\hline Aedes quasirubithorax ${ }^{[?]}$ & 0 & 0 & 3 & 3 & 2 & 0 & 0 & 2 & 5 \\
\hline Aedes quinquelineatus ${ }^{[?]}$ & 16 & 14 & 0 & 30 & 66 & 17 & 3 & 86 & 116 \\
\hline Aedes tremulus $\left.{ }^{[\mathrm{a}, \mathrm{b}, \mathrm{l}}\right]$ & 10 & 2 & 3 & 15 & 3 & 1 & 0 & 4 & 19 \\
\hline Aedes vigilax ${ }^{[a, b, d, e]}$ & 86 & 106 & 108 & 300 & 45 & 57 & 71 & 173 & 473 \\
\hline Anopheles annulipes (s.l.) ${ }^{[a, c, d, e]}$ & 1 & 0 & 4 & 5 & 3 & 3 & 5 & 11 & 16 \\
\hline Anopheles bancroftii [c,e] & 0 & 0 & 0 & 0 & 1 & 0 & 0 & 1 & 1 \\
\hline Anopheles farauti $[\mathrm{b}, \mathrm{c}, \mathrm{e}]$ & 8 & 58 & 99 & 165 & 3 & 10 & 9 & 22 & 187 \\
\hline Coquillettidia nr.crassipes ${ }^{[c, f]}$ & 95 & 49 & 7 & 151 & 6 & 7 & 4 & 17 & 168 \\
\hline Culex annulirostris $[a, b, d, e, g]$ & 390 & 456 & 544 & 1390 & 38 & 77 & 125 & 240 & 1630 \\
\hline Culex bitaeniorhynchus ${ }^{[b, e]}$ & 0 & 1 & 0 & 1 & 0 & 0 & 0 & 0 & 1 \\
\hline Culex cubiculi ${ }^{[?]}$ & 0 & 0 & 0 & 0 & 0 & 1 & 0 & 1 & 1 \\
\hline Culex gelidus ${ }^{[a, b]}$ & 2 & 36 & 115 & 153 & 0 & 1 & 6 & 7 & 160 \\
\hline Culex hilli ${ }^{[?]}$ & 12 & 18 & 2 & 32 & 6 & 5 & 0 & 11 & 43 \\
\hline Culex pullus ${ }^{[b]}$ & 16 & 26 & 12 & 54 & 0 & 1 & 1 & 2 & 56 \\
\hline Culex sitiens $^{[\mathrm{e}]}$ & 5 & 6 & 12 & 23 & 10 & 5 & 7 & 22 & 45 \\
\hline Mansonia septempunctata ${ }^{[a]}$ & 5 & 4 & 27 & 36 & 0 & 1 & 3 & 4 & 40 \\
\hline Mansonia uniformis $[a, b, e, f]$ & 0 & 2 & 1 & 3 & 0 & 0 & 0 & 0 & 3 \\
\hline Tripteroides atripes ${ }^{[?]}$ & 0 & 1 & 0 & 1 & 0 & 0 & 0 & 0 & 1 \\
\hline Tripteroides magnesianus ${ }^{[?]}$ & 4 & 2 & 0 & 6 & 6 & 0 & 0 & 6 & 12 \\
\hline Tripteroides sp. & 4 & 6 & 0 & 10 & 3 & 0 & 0 & 3 & 13 \\
\hline Verrallina carmenti ${ }^{[a]}$ & 20 & 4 & 0 & 24 & 13 & 27 & 3 & 43 & 67 \\
\hline Verrallina funerea ${ }^{[a, b, g]}$ & 0 & 1 & 0 & 1 & 0 & 0 & 0 & 0 & 1 \\
\hline Verrallina lineata ${ }^{[a]}$ & 353 & 193 & 71 & 617 & 31 & 41 & 10 & 82 & 699 \\
\hline Total & 1200 & 1152 & 1139 & 3491 & 384 & 339 & 290 & 1013 & 4504 \\
\hline
\end{tabular}

a alphaviruses (may cause Barmah Forest, chikungunya, Ross River, Sindbis)

b flaviviruses (may cause dengue, Murray Valley-, Australian-, Kunjin- \& Japanese encephalitis; yellow fever, Edge Hill, West Nile)

c Plasmodium spp. (may cause human and/or avian malaria)

d Dirofilaria immitus (may cause dog heartworms)

e Wuchereria bancrofti (may cause filariasis in humans)

f Brugia malayi (may cause filariasis in humans)

g Orbivirus spp. (may cause epizootic hemorrhagic disease in ruminants \& macropods)

? unknown

Table S2, S3, S4, S5). The genera Aedes recorded the highest number of species (10 spp.), whereas Culex spp. were captured most frequently (1936 individuals). Four species dominated the total samples, together contributing to $74 \%$ of the captures; Culex annulirostris (36\%), Verrallina lineata (16\%), Aedes notoscriptus (11\%) and Aedes vigilax (11\%). The most dominant species in the wet season were
Cx. annulirostris and Ve. lineata. During the dry season, $C x$. annulirostris was again the most abundant species, followed by Ae. notoscriptus. Some species, such as Ae. alternans, were only captured during the wet season and other species, such as Ae. lineatopennis were predominantly trapped during the dry season (Table 2). Mean mosquito species richness was similar in all habitats (2-way 
ANOVA $\left.F_{(2,18)}=0.692, P=0.514\right)$ but differed significantly between the seasons (Fig. 3). More species were captured in the wet season than in the dry season (2way ANOVA $\left.F_{(1,18)}=15.720, P=0.001\right)$. There was no significant interaction between habitat and season (2way ANOVA $\left.F_{(2,18)}=0.692, P=0.514\right)$. Species accumulation curves from our sampling design show the difference in species capture rate between the three habitats. The asymptotes of the curves suggest that our traps captured all the attracted species present in the habitats. However, it is possible that we did not trap either rare species or those not attracted to the traps or bait used (Fig. 4).

\section{Mosquito community composition}

Using ordination analyses, we examined the mosquito community composition in three ways. First, we combined data for the wet and dry season (Fig. 5a) and determined that the mosquito community varied in response to habitat type, especially between forest interior and grassland sites (PerMANOVA: pseudo $F=2.164$, $P=0.028$ ). The NMS Axis 1 (which captured $45 \%$ of the total variation) and Axis 2 (capturing $42 \%$ of the variation) both discriminated mosquito communities in forest interiors that differed from those in grasslands. Of the 22 species examined, 6 were significantly correlated

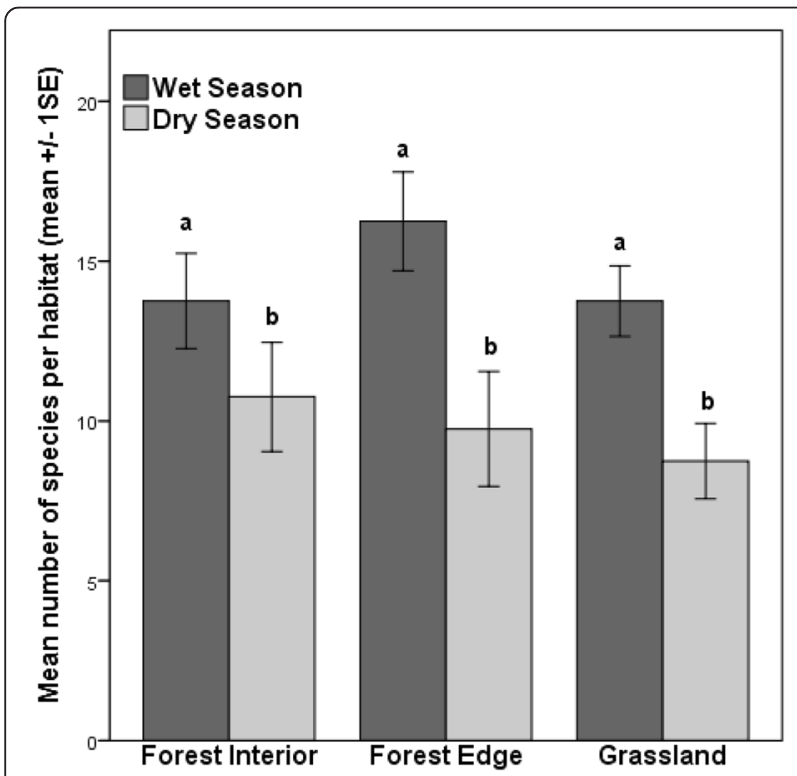

Fig. 3 Mean number of mosquito species in the three sampled habitats. Mean number of mosquito species captured in forest interior, forest edge and grassland habitats during the wet and dry season in each habitat. Mean species richness was quite similar between the three habitats but significantly fewer species were captured in the dry season compared to the wet season, especially along forest edges and grassland sites. Error bars denote the standard error. Different letters denote significant differences

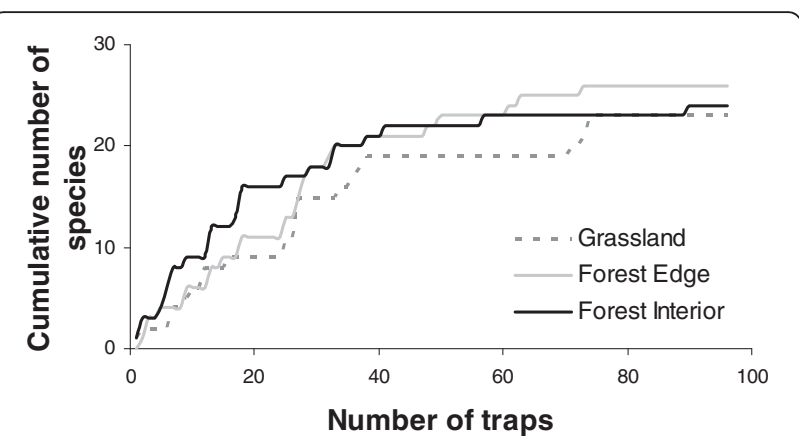

Fig. 4 Species accumulation curves for sampled mosquitoes. Species accumulation curves for mosquitoes sampled from forest interior, forest edge and grassland habitats suggest that most common species were captured. The curves display adequate sampling effort for all habitats and indicate that further sampling would not have produced the discovery of more species, except for very rare ones

with these axes (Table 3). Secondly, when we explored the influence of seasonality on the community structure and found an identical and significant pattern of rainforest and grassland separation: (wet season PerMANOVA: pseudo $F=2.274, P=0.028$ ) and (dry season PerMANOVA: pseudo $F=1.608, P=0.026)$. The wet season ordination (Fig. 5b) explained $91 \%$ of the variation in the data (Axis 1: $55 \%$, Axis 2: $36 \%$ ), with 21 species examined and 8 significantly correlated with these axes (Table 3). The dry season analysis (Fig. 5c) explained $93 \%$ of the total variation in the data set with 6 out of 19 species significantly correlated with these axes (Table 3). In summary, all three ordination analyses revealed that the mosquito communities were different between forest interior and grassland sites and that an overlap in species composition existed between forest interior and forest edge sites and between grassland and forest edge sites.

\section{Mosquito vector community}

We further examined the habitat preference of known disease vectors- mosquito species capable of transmitting alpha-, flaviviruses and protozoans and found a significant difference between rainforest interior and grassland sites (Fig. 6). The two ordination axes collectively explained $87.1 \%$ of the total variation with 8 species significantly correlated with these axes (PerMANOVA: pseudo $F=$ 2.502, $P=0.029$ ) (Table 3). Notably, we observed more known disease vectors in grasslands than in forest habitats. We further investigated the mosquito community structure of each habitat type by examining species dominance using rank abundance diagrams (Fig. 7a, b and c). Overall, $C x$. annulirostris was the most dominant species. During the wet season, it dominated grasslands and forest edges, and shared dominance of rainforest interiors with Ve. lineata. In the dry season, $C x$. annulirostris 

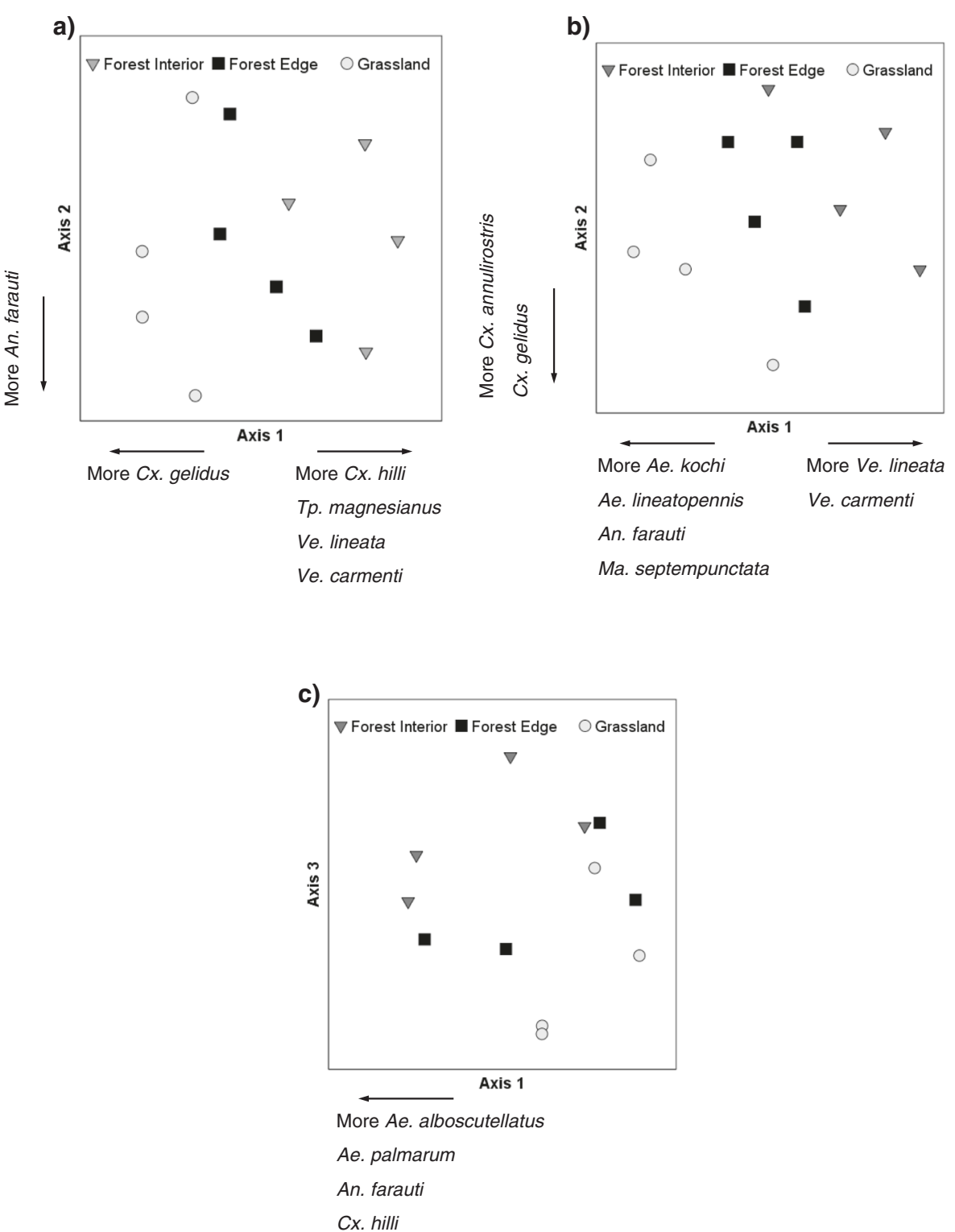

Fig. 5 Ordination analyses of mosquito communities for habitats and seasons. Ordination analyses (NMS) show that the mosquito community varied strongly in response to habitat type. Forest interior sites are distinctly different from grassland sites when (a) the data for the wet season and dry season were combined, the data for the wet season (b) and the dry season (c) (only two of the three dimensions obtained in the analysis are displayed) were analysed separately

continued to dominate the grasslands but shared dominance of forest edges with the rainforest species $A$ e. notoscriptus. Only one species dominated rainforest interior (Ae. notoscriptus).

\section{Mosquito characteristics}

We found that ecological and biological characteristics strongly influenced mosquito captures in the study area. Commonly captured mosquitoes ( $>40$ individuals) had a wide geographical range (Fig. 8a), were ground water breeders (Fig. 8b) and nocturnal blood-feeders (Fig. 8c).
The mosquito group which has a wide geographical range in Australia was captured nearly three times more than the second most common group (the very restricted range group) (2-way ANOVA $F_{(3,36)}=75.045$, $P<0.0001)$. All groups were significantly different from each other (Tukey HSD post-hoc tests $P<0.018$ ). No differences in mean captures occurred in the three habitats (2-way ANOVA $F_{(2,36)}=0.163, P=0.85$ ); however, there was an interaction effect between groups and habitat (2way ANOVA $\left.F_{(6,36)}=5.286, P=0.001\right)$, with rainforest habitats supporting more species with a very restricted 
Table 3 Pearson correlations for mosquito species with two or three ordination axes produced by nonmetric multidimensional scaling (NMS). Correlation values in boldface were significant $(P<0.005)$ using a Bonferroni-corrected alpha value. *Mosquito community (all species were used for the analysis); ${ }^{* *}$ Vector Community (only species capable of vectoring alpha-, flaviviruses and protozoans were considered for the analysis); ${ }^{* * *}$ All Seasons (wet and dry seasons combined)

\begin{tabular}{|c|c|c|c|c|c|c|c|c|c|}
\hline \multirow[b]{3}{*}{ Species } & \multicolumn{7}{|c|}{ Mosquito Community* } & \multirow{2}{*}{\multicolumn{2}{|c|}{$\frac{\text { Vector Community** }}{\text { All Seasons*** }}$}} \\
\hline & \multicolumn{2}{|c|}{ All Seasons ${ }^{* * *}$} & \multicolumn{2}{|c|}{ Wet Season } & \multicolumn{3}{|c|}{ Dry Season } & & \\
\hline & Axis 1 & Axis 2 & Axis 1 & Axis 2 & Axis 1 & Axis 2 & Axis 3 & Axis 1 & Axis 2 \\
\hline Aedes alboscutellatus & & & & & -0.871 & 0.319 & 0.246 & & \\
\hline Aedes kochi & & & -0.784 & 0.096 & & & & -0.811 & -0.062 \\
\hline Aedes lineatopennis & & & -0.762 & 0.281 & & & & -0.767 & 0.248 \\
\hline Aedes palmarum & & & & & -0.866 & -0.088 & -0.103 & & \\
\hline Aedes quinquelineatus & & & & & -0.796 & 0.387 & 0.087 & & \\
\hline Aedes vigilax & & & & & 0.15 & 0.787 & 0.023 & & \\
\hline Anopheles farauti & -0.37 & -0.854 & -0.769 & 0.47 & & & & -0.879 & 0.325 \\
\hline Cq. nr. crassipes & & & & & & & & 0.081 & 0.786 \\
\hline Culex annulirostris & & & 0.039 & -0.793 & & & & & \\
\hline Culex gelidus & -0.845 & 0.441 & -0.393 & -0.791 & & & & -0.289 & -0.902 \\
\hline Culex hilli & 0.799 & 0.235 & & & -0.839 & 0.005 & 0.243 & & \\
\hline Mansonia septempunctata & & & -0.837 & 0.131 & & & & -0.865 & 0.013 \\
\hline Tripteroides magnesianus & 0.792 & -0.278 & & & & & & & \\
\hline Verrallina carmenti & 0.775 & -0.508 & 0.77 & 0.257 & & & & 0.183 & 0.921 \\
\hline Verrallina lineata & 0.815 & 0.357 & 0.777 & 0.14 & -0.194 & -0.789 & 0.529 & 0.82 & 0.301 \\
\hline
\end{tabular}

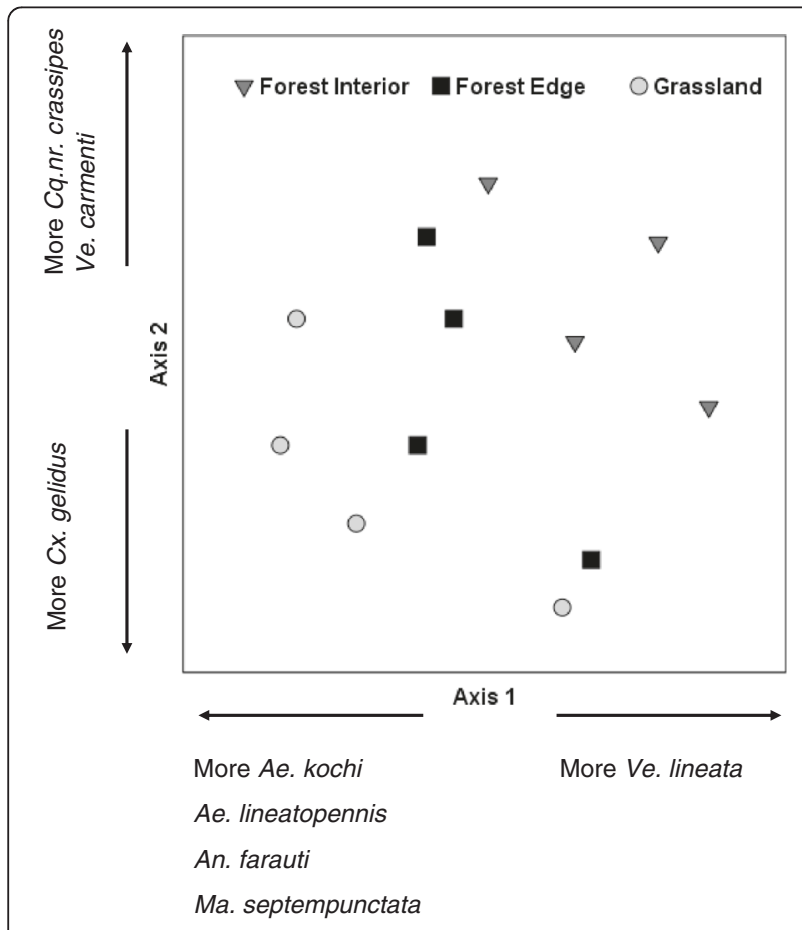

Fig. 6 Ordination analysis of the vector community. Ordination analysis (NMS) of the vector community displays a distinctly different species composition for forest interior and grassland sites range than the other habitats. Mosquitoes which belong to the group of groundwater breeders were captured six times more often than container breeders (2-way ANOVA $\left.F_{(1,18)}=106.086, P<0.0001\right)$. Habitat type had no influence on mean captures (2-way ANOVA $F_{(2,18)}=0.173, P=$ 0.842 ) and there was no interaction effect between groups and habitat type (2-way ANOVA $\left.F_{(2,18)}=2.070, P=0.155\right)$. We found that there was a significant difference of time of feeding amongst the collected mosquitoes (2-way ANOVA $\left.F_{(2,27)}=12.459, P<0.0001\right)$. Mosquitoes captured in this study blood-feed predominantly at night (54\%), followed by the crepuscular group (28\%) and the diurnal group (18\%). Nocturnal and diurnal feeders differed significantly (Tukey HSD post-hoc test $P<0.0001$ ) as did nocturnal and crepuscular feeders (Tukey HSD posthoc test $P=0.004)$. There was no significant difference between the diurnal and crepuscular group (Tukey HSD post-hoc test $P=0.431)$. Habitat had no influence on the mean captures (2-way ANOVA $F_{(2,27)}=2.522, P=$ 0.099 ) and no interaction effect was detected (2-way ANOVA $\left.F_{(4,27)}=1.613, P=0.200\right)$.

\section{Discussion}

Communities in naturally-occurring ecotones are often an integration of species from adjacent habitats [44]. We observed a similar pattern in mosquito communities although across an anthropogenic disturbance gradient from tropical grassland to rainforest, where 
a) Wet \& Dry Season
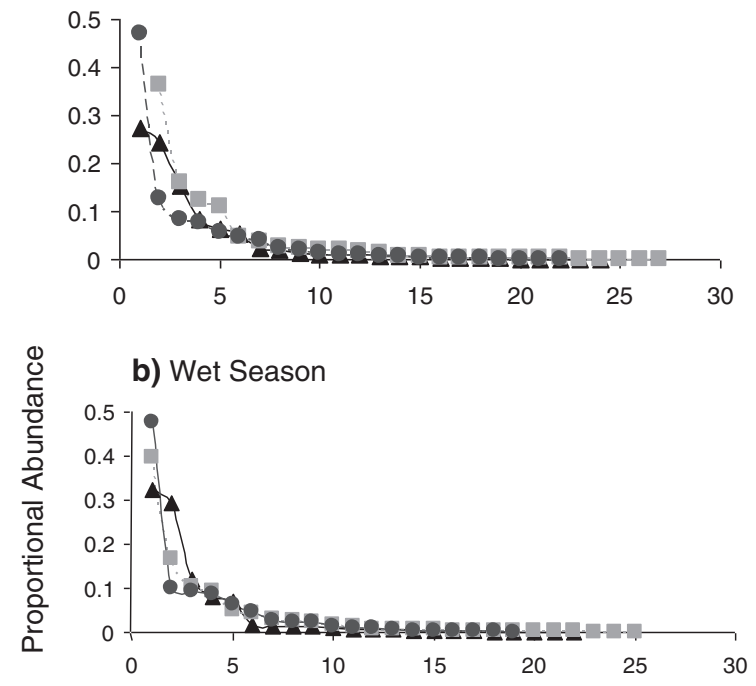

c) Dry Season

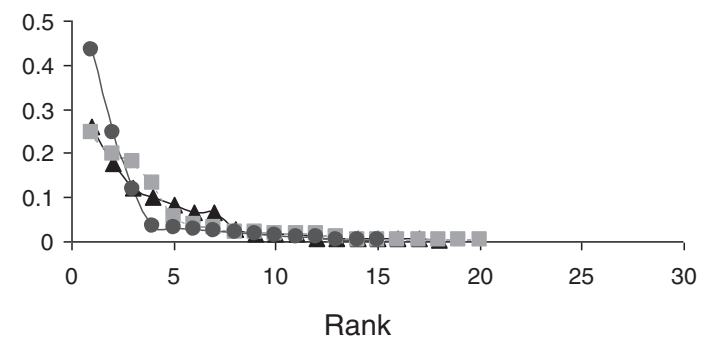

$\Delta$ Forest Interior $\square$ Forest Edge $\bullet$ Grassland

Fig. 7 Rank-abundance diagrams for the diversity of mosquito species. Rank-abundance diagrams displaying the diversity of mosquito species in the three habitats; taking into account not just the number of species (richness) but also the distribution of individuals among species (evenness). Overall (a) (wet and dry season combined) forest interior had 2 dominant species; forest edge and grassland had one dominant species. In the wet season (b) two dominant species were discovered in the forest interior but only one dominant species in both grassland and forest edge. During the dry season sampling (c) one dominant species was captured in the grassland and forest edge and two species dominated the forest interior

forest edges supported mosquito species from both habitats. This landscape pattern continued throughout the year, despite a seasonal influence on mosquito abundances. The majority of the mosquitoes at our study area showed significant traits such as groundwater breeders, nocturnal blood-feeders and a wide geographic distribution across Australia. Our analysis of disease risk found a significant difference between grassland and forest habitat, with a greater abundance of known disease vectors in grasslands.
Forest edges acting as ecotones, may produce a novel juxtaposition of mosquito communities which could have wide-reaching consequences for mosquito-borne disease transmission [45] as an increase of endemic viruses is more likely to occur in disturbed habitats than in pristine primary forests. For instance, Junglen et al. [46] found that the mosquito genera Aedes, Anopheles and Culex were more commonly encountered in disturbed habitats and contained more virus isolates than forest mosquitoes.

We found edges are hot beds of potentially disease vectoring species and that they have an important role in facilitating disease transmission across the landscape. Disturbed and degraded habitats are avoided by numerous forest species [47-49]. However some, especially invasive and generalist species seem to prefer these habitats $[50,51]$ which may explain why the mosquito community composition was significantly different between man-made grasslands and forest interior sites in our study. A previous, short-term study we conducted in the same area [41] also showed that grasslands supported a markedly different community to inside forests. These distinct differences in mosquito community composition between grassland and forest interior sites may be because certain mosquito species (e.g. An. farauti and Cx. gelidus) find open habitats such as grasslands more attractive than closed habitats.

The question that then arises is "why do some mosquitoes prefer open habitats to closed habitats"? The answer might be that open and disturbed habitats feature environmental characteristics such as higher temperatures and light levels, higher $\mathrm{pH}$ - and lower salt levels, which can accelerate larval growth and increase larval survivorship. These changing environmental conditions also contribute to faster growth of algae - an important food source for mosquito larvae [4, 8-11].

It was not unexpected that more mosquitoes and species were captured in the wet season compared to the dry season. Mosquitoes are commonly associated with rainfall $[3,52]$. However, it was surprising to find that some important disease vectors such as Ae. notoscriptus, Ae. vigilax, An. farauti and Cx. annulirostris in our study area were able to persist in the dry season. This suggests that disease transmission could potentially occur at any time of the year.

Previous studies have found that refugia with favourable microclimatic conditions may help a mosquito population to persist year round. For example, Hightower et al. [53] found that malaria vectors (Anopheles spp.) in Kenya retreat to vegetation around permanent water bodies during the dry season, allowing for year round reproduction. Water-filled tree holes and abandoned snail shells can also be used for oviposition [54]. Additionally, anthropogenic changes to the environment like the construction of 

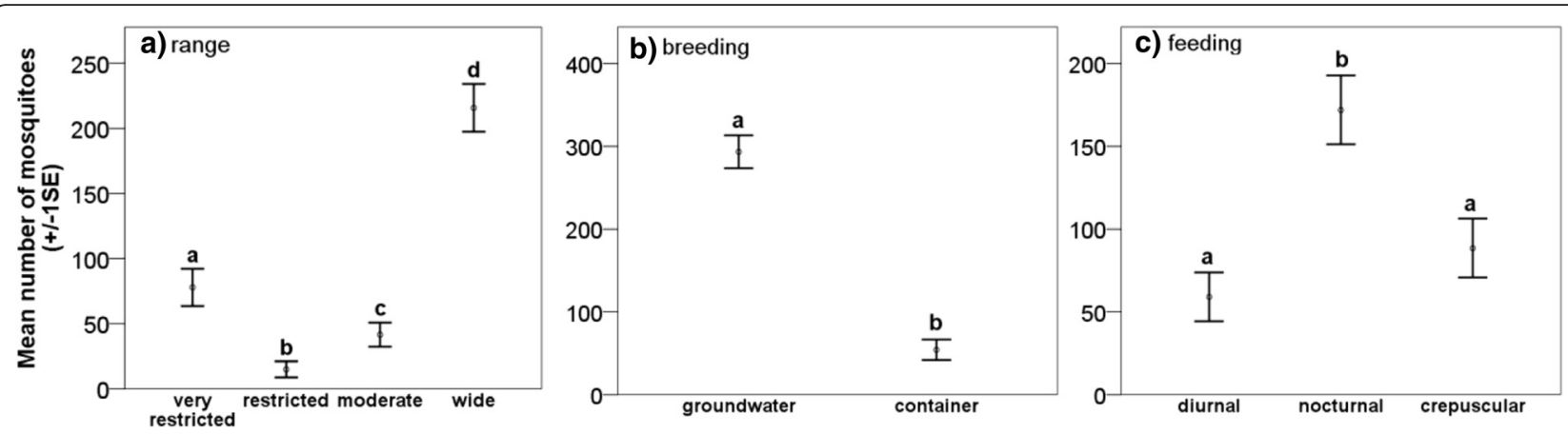

Fig. 8 Mosquito characteristics. Mean number of captured mosquito groups in regards to geographical range, breeding habitat and time of feeding in northern Australia. Most captures were from the mosquitoes which have a wide distribution (a), use groundwater environments for depositing eggs (b) and blood-feed mainly during the night (c). Different letters denote significant differences

irrigation areas and dams allow mosquitoes to breed regardless of seasons [55-58]. Jardine et al. [59] demonstrated that the Ord River Irrigation Area in Western Australia is responsible for mosquitoes breeding even during the driest month of the year. For example, $C x$. annulirostris, the most abundant species in our study and responsible for transmitting numerous viruses, (Ross River, Kunjin, Murray Valley and Japanese encephalitis) $[60,61]$ was found to be very active during the dry season [59].

There may be other mechanisms that contribute to the year-round persistence of mosquitoes. Biological, physiological and ecological attributes such as desiccationresistant eggs, egg dormancy, diapause and larval development in moist soil, leaf litter or plant axils and adult and larvae hibernation, aestivation, quiescence and diapause could be mechanisms for survival in environments with seasonal periods of droughts [54, 62-65]. Additionally, some adult mosquitoes are able to aestivate by gonotrophic dissociation (the pausing of egg production despite acquiring several blood meals) or by performing diapause [66-70]. Lastly, man-made and natural shelters may provide refugia for inactive parous (having laid eggs at least once) female mosquitoes [71]. Captured mosquitoes from our study most likely used one or a combination of the strategies outlined above to persist year-round. For example, Ae. notoscriptus has both desiccation-resistant eggs and the ability to perform hibernation and diapause during larval and adult life stages [72, 73]. However, the eggs of $C x$. annulirostris, the most dominant species in this study, are prone to desiccation [25]; but adults can perform diapause [68] and are known to lay eggs in shallow, grassy pools only hours after a rainfall event [74]. This is in accordance with the findings of this study as most $C x$. annulirostris were captured in grasslands.

We expected that mosquito species richness would be highest in forest interior habitats as tropical forests often support greater diversity within forest interiors and decline along forest edges [47-49]. However, this pattern was not observed in this study for mosquito diversity. In contrast, the number of species was quite evenly distributed across the three habitat types. Even though the sampling effort was sufficient, rare species, most notably canopy specialists, could be absent from our samples as a consequence of the trap height used $(\sim 1.5 \mathrm{~m})$. More extensive sampling at different vertical strata would most likely increase the probability of capturing such rare species in future studies [75].

We believe that it is crucial to comprehend the impacts of landscape disturbance, especially the impacts of deforestation and forest fragmentation, on mosquito communities. Commonly-captured mosquito species in our study were found to be widespread in geographic distribution, ground breeders and nocturnal feeders. We consider the current distribution of these species to be the result of land clearing and agriculture (predominantly sugar cane). Prior to European arrival, tropical rainforests, open eucalypt forests and estuarine vegetation blanketed the region [76], and the mosquito communities probably included species that were more restricted in distribution to the different habitats.

Our observations of changing mosquito communities in response to land use support the concept that new or re-emergent mosquito-borne diseases could arise in areas where land use changes occur. Disease transmission will almost certainly emerge via common mosquito species captured across all habitats and seasons (e.g. $C x$. annulirostris) or through species more prolific within open habitats, such as man-made grasslands (e.g. An. farauti, Cx. gelidus, Ma. septempunctata) [41]. Previous studies from tropical areas have already demonstrated that human-induced land use changes, such as deforestation, are responsible for a rise in important disease vectors such as Anophelinae and Aedinae [3, 77-79]. However, our study is the first to suggest that common 
species and species which are potential disease vectors can maintain populations across a land use gradient throughout the year.

\section{Conclusions}

We demonstrated that the mosquito community in north Queensland strongly responded to anthropogenic land use changes. Our results displayed that there is a diverse mosquito community in tropical Australia, but more importantly that the community composition varies considerably between forests and disturbed habitats. Additionally, most disease transmitting species predominantly occur in grasslands created by humans. This strong influence of anthropogenic land use change on mosquito communities could have potential implications for pathogen transmission to humans and wildlife. We also found that vectors of mosquito-borne diseases, such as $C x$. annulirostris, can persist all year round, further increasing disease risk. Considering that human-induced land use changes and human population growth are advancing rapidly in tropical regions, it is of the utmost importance to predict future disease risk. Historically, mosquito studies have been predominantly focused on single species lifecycles in association with the urban environment, we suggest further ecological studies are necessary to understand how land use changes will influence disease dynamics of the whole community in order to predict and prevent future health threats.

\section{Additional file}

Additional file 1: Table S1. Abundance. Table S2. Dry Season 1. Table S3. Dry Season 2. Table S4. Wet Season 1. Table S5. Wet Season 2 (XLS $83.5 \mathrm{~kb})$

\section{Abbreviations}

ANOVA, analysis of variance; NMS, nonmetric multidimensional scaling ordination; PerManova, permutational multivariate analysis of variance; Tukey HSD, Tukey Honest Significant Difference post-hoc test.

\section{Acknowledgements}

We are grateful to John Clancy and Paul Zborowski who provided assistance in mosquito identification, and John Bosworth, Roger Steiger and Sandra Taylor for field work. This research was supported by an Australian Postgraduate Award to DM and grants to SL from the Torres Strait Regional Authority, National Environmental Research Program, James Cook University, Reef and Rainforest Research Centre and the Australian Research Council Future Fellowship.

\section{Funding}

This research was supported by an Australian Postgraduate Award to DM and grants to SL from the Torres Strait Regional Authority, National Environmental Research Program, James Cook University, Reef and Rainforest Research Centre and the Australian Research Council Future Fellowship.

\section{Availability of data and materials}

The datasets supporting the conclusions of this article are provided in Additional file 1.

\section{Authors' contributions}

DM, SL, SR conceived and designed the study. DM carried out the field collections and analysed the data. DM, SL and SR drafted the manuscript and read, critically revised and approved the final manuscript.

\section{Competing interests}

The authors declare that they have no competing interests.

\section{Consent for publication}

Not applicable.

Ethics approval and consent to participate

Not applicable.

\section{Author details}

${ }^{1}$ Centre for Tropical Environmental and Sustainability Studies (TESS) and College of Marine and Environmental Sciences, James Cook University, 4870 Cairns, Queensland, Australia. ${ }^{2}$ School of Public Health, Tropical Medicine and Rehabilitative Sciences, James Cook University, 4870 Cairns, Queensland, Australia.

Received: 29 February 2016 Accepted: 29 June 2016

Published online: 07 July 2016

\section{References}

1. Morse S. Factors in the emergence of infectious diseases. Emerg Infect Dis. 1995;1:7-15.

2. Gubler D. Resurgent vector-borne diseases as a global health problem. Emerg Infect Dis. 1998;4:442-50.

3. Patz J, Graczyk T, Geller N, Vittor A. Effects of environmental change on emerging parasitic diseases. Int Journal Parasitol. 2000;30:1395-405.

4. Vittor AY, Pan W, Gilman RH, Tielsch J, Glass G, Shields T, Sanchez-Lozano W, Pinedo W, Salas-Cobos E, Flores S, Patz JA. Linking deforestation to malaria in the Amazon: characterization of the breeding habitat of the principal malaria vector, Anopheles darlingi. Am J Trop Med Hyg. 2009;81:5-12.

5. Foley J, Asner G, Costa M, Coe M, DeFries R, Gibbs H, Howard E, Olson S, Patz J, Ramankutty N. Amazonia revealed: forest degradation and loss of ecosystem goods and services in the Amazon Basin. Front Ecol Environ. 2007;5:25-32.

6. Bayoh M, Lindsay S. Effect of temperature on the development of the aquatic stages of Anopheles gambiae sensu stricto (Diptera: Culicidae). B Entomol Res. 2003;93:375-81.

7. Norris D. Mosquito-borne diseases as a consequence of land use change. Eco Health. 2004:1:19-24.

8. Tuno N, Okeka W, Minakawa N, Takagi M, Yan G. Survivorship of Anopheles gambiae sensu stricto (Diptera: Culicidae) larvae in western Kenya highland forest. J Med Entomol. 2005;42:270-7.

9. Camargo JLC, Kapos V. Complex edge effects on soil moisture and microclimate in central Amazonian forest. J Trop Ecol. 1995;11:205-21.

10. Ye-Ebiyo Y, Pollack R, Kiszewski A, Spielman A. Enhancement of development of larval Anopheles arabiensis by proximity to flowering maize (Zea mays) in turbid water and when crowded. Am J Trop Med Hyg. 2003; 68:748-52.

11. Bond J, Arredondo-Jiménez J, Rodríguez M, Quiroz-Martínez H, Williams T. Oviposition habitat selection for a predator refuge and food source in a mosquito. Ecol Entomol. 2005;30:255-63.

12. Amerasinghe F, Ariyasena T. Larval survey of surface water-breeding mosquitoes during irrigation development in the Mahaweli project. Sri Lanka J Med Entomol. 1990:27:789-802.

13. Harb M, Faris R, Gad A, Hafez O, Ramzy R, Buck A. The resurgence of lymphatic filariasis in the Nile delta. Bull WHO. 1993;71:49-54.

14. Schrag SJ, Wiener P. Emerging infectious disease: what are the relative roles of ecology and evolution? Trends Ecol Evol. 1995;10:319-24.

15. Daszak P, Cunningham AA, Hyatt AD. Anthropogenic environmental change and the emergence of infectious diseases in wildlife. Acta Trop. 2001;78: 103-16.

16. Spielman A, D'Antonio M. Mosquito: a natural history of our most persistent and deadly foe. New York: Hyperion; 2001

17. Barrett AD, Monath TP. Epidemiology and ecology of yellow fever virus. Adv Virus Res. 2003:61:291-315.

18. Strode GK. Yellow fever. New York: McGraw-Hill; 1951. 
19. Hanna JN, Ritchie SA, Richards AR, Taylor CT, Pyke AT, Montgomery BL, et al. Multiple outbreaks of dengue serotype 2 in north Queensland, 2003/04. Aus N Z J Public Health. 2006;30:220-5.

20. Luz P, Mendes MBV, Codeço CT, Struchiner CJ, Galvani AP. Time series analysis of dengue incidence in Rio de Janeiro, Brazil. Am J Trop Med Hyg. 2008;79:933-9.

21. Wongkoon S, Jaroensutasinee M, Jaroensutasinee K. Distribution, seasonal variation \& dengue transmission prediction in Sisaket, Thailand. Indian J Med Res. 2013;138:347.

22. Longbottom H. Epidemiology of malaria in Australia 1991-1995. Commun Dis Intell. 1996;20:84-7.

23. Bryan J, Fa'afoi E, Forsyth S. Report of the Australian Malaria Register for 1992 and 1993. Commun Dis Intell. 1998:22:237-44.

24. Hanna J, Brookes D, Ritchie S, van den Hurk A, Loewenthal M. Malaria and its implications for public health in far north Queensland: a prospective study. Aus NZ J Public Health. 1998;22:196-9.

25. Lee DJ, Hicks M, Griffiths M, Russell R, Marks E. The Culicidae of the Australasian Region, vol. 1-12. Canberra: Australian Government Publishing Service; 1989.

26. Johnson D, Druce J, Chapman S, Swaminathan A, Wolf J, Richards J, et al. Chikungunya virus infection in travellers to Australia. Medical J Aust. 2008;188:41-3.

27. van den Hurk A, Hall-Mendelin S, Pyke A, Smith G, Mackenzie J. Vector competence of Australian mosquitoes for chikungunya virus. Vector Borne Zoonot Dis. 2010;10:489-95.

28. Mackenzie J, Broom A, Hall R, Johansen C, Lindsay M, Phillips D, Ritchie S, Russell R, Smith D. Arboviruses in the Australian region, 1990 to 1998. Commun Dis Intell. 1998;22:93-9.

29. Department of Infrastructure and Planning. 2009. Far North Queensland Regional Plan 2031. Queensland Dept of Infrastructure and Planning, Brisbane.

30. Bohnet IC, Pert PL. Patterns, drivers and impacts of urban growth: A study from Cairns, Queensland, Australia from 1952 to 2031. Landsc Urban Plan. 2010;97:239-48.

31. Reiter $P$, Sprenger $D$. The used tire trade: a mechanism for the worldwide dispersal of container breeding mosquitoes. J Am Mosq Control Assoc. 1987:3:494.

32. Mitchell C. Geographic spread of Aedes albopictus and potential for involvement in arbovirus cycles in the Mediterranean basin. J Vector Ecol. 1995:20:44-58.

33. Daly MT, Stimson RJ, Jenkins O. Tourism and foreign investment in Australia: trends, prospects and policy implications. Aust Geogr Stud. 1996;34:169-84.

34. Knope K, Whelan P, Smith D, Nicholson J, Moran R, Doggett S, et al. Arboviral diseases and malaria in Australia, 2010-11: Annual report of the National Arbovirus and Malaria Advisory Committee. Commun Dis Intell Quarterly Report. 2013;37:1.

35. Tracey J. The vegetation of the humid tropical region of North Queensland. Melbourne: CSIRO; 1982

36. Keto A, Scott K. Tropical rainforests of North Queensland: their conservation significance. Canberra: Australian Government Publishing Service; 1986.

37. Griggs P. Deforestation and sugar cane growing in Eastern Australia, 18601995. Environ Hist. 2007;13:255-83.

38. Kline DL. Traps and trapping techniques for adult mosquito control. J Am Mosq Control Assoc. 2006;22:490-6

39. van den Hurk A, Richtie S, Montgomery B. The mosquitoes of North Queensland: identification and biology. Brisbane: Queensland Health, Queensland Government; 1999. p. 1999.

40. Ehlers $\mathrm{G}$, editor. Common mosquitoes of north Queensland. Kirwan: Mosquito Control Association of Australia; 2011.

41. Meyer Steiger D, Johnson P, Hilbert DW, Ritchie S, Jones D, Laurance SGW. Effects of landscape disturbance on mosquito community composition in tropical Australia. J Vector Ecol. 2012;37:69-76.

42. Chandler RC. Practical considerations in the use of simultaneous inference for multiple tests. Anim Behav. 1995:49:524-7.

43. Anderson MJ. A new method for non-parametric multivariate analysis of variance. Austr J Ecol. 2001:26:32-46.

44. Fortin MJ, Olson R, Ferson S, Iverson L, Hunsaker C, Edwards G, et al. Issues related to the detection of boundaries. Landscape Ecol. 2000;15:453-66.

45. Despommier D, Ellis BR, Wilcox BA. The role of ecotones in emerging infectious diseases. EcoHealth. 2006:3:281-9.

46. Junglen S, Kurth A, Kuehl H, Quan P, Ellerbrok H, Pauli G, et al. Examining landscape factors influencing relative distribution of mosquito genera and frequency of virus infection. EcoHealth. 2009;6:239-49.
47. Laurance S. Responses of understory rain forest birds to road edges in central Amazonia. Ecol Appl. 2004;14:1344-57.

48. Ernst R, Rödel M. Patterns of community composition in two tropical tree frog assemblages: separating spatial structure and environmental effects in disturbed and undisturbed forests. J Trop Ecol. 2008;24:111-20.

49. Hillers $A$, Veith $M$, Rödel $M$. Effects of forest fragmentation and habitat degradation on West African leaf litter frogs. Conserva Biol. 2008;22:762-72.

50. Brown JRK, Hutchings R. Disturbance, fragmentation, and the dynamics of diversity in Amazonian forest butterflies. In: Laurance WF, Bierregaard JR, editors. Tropical forest remnants: ecology, management, and conservation of fragmented communities. Chicago: University of Chicago Press; 1997. p. 91-110.

51. Dranzoa C. The avifauna 23 years after logging in Kibale National Park, Uganda. Biodivers Conserv. 1998;7:777-97.

52. Russell RC. Mosquito-borne arboviruses in Australia: the current scene and implications of climate change for human health. Intl J Parasitol. 1998;28:955-69.

53. Hightower A, Ombok M, Otieno R, Odhiambo R, Oloo A, Lal A, et al. A geographic information system applied to a malaria field study in Western. Kenya Am J Trop Med Hyg. 1998;58:266-72.

54. Lounibos L. Habitat segregation among African treehole mosquitoes. Ecol Entomol. 1981;6:129-54.

55. Mulla M, Mian L, Gratz N. Agricultural management practices: their impacts on production of vector and pest mosquitoes. J Agr Entomol. 1987;4:97-131.

56. Ghebreyesus TA, Haile M, Witten KH, Getachew A, Yohannes AM, Yohannes M, et al. Incidence of malaria among children living near dams in northern Ethiopia: community based incidence survey. Brit Med J. 1999:319:663-6.

57. Singh N, Mehra R, Sharma V. Malaria and the Narmada-river development in India: a case study of the Bargi dam. Ann Trop Med Parasit. 1999;93:477-88.

58. McMichael A. Human culture, ecological change and infectious disease. Ecosyst Health. 2001;7:107-15.

59. Jardine A, Lindsay M, Heyworth J, Weinstein P. Dry-season mosquito breeding associated with irrigation in the northeast Kimberley region of Western Australia: potential impact on mosquito-borne disease transmission. EcoHealth. 2004;1:387-98.

60. Marshall ID. Murray Valley and Kunjin encephalitis. In: Monath TP, editor. The arboviruses: epidemiology and ecology. Boca Raton: CRC Press; 1998. p. 151-91.

61. van den Hurk AD, Nisbet D, Hall R, Kay B, Mackenzie J, Ritchie S. Vector competence of Australian mosquitoes (Diptera: Culicidae) for Japanese encephalitis virus. J Med Entomol. 2003:40:82-90.

62. Beier J, Copeland R, Oyaro C. Anopheles gambiae complex egg-stage survival in dry soil from larval development sites in western Kenya. J Am Mosq Control Assoc. 1990;6:105-9.

63. Minakawa N, Githure Jl, Beier JC, Yan G. Anopheline mosquito survival strategies during the dry period in western Kenya. J Med Entomol. 2001;38:388-92.

64. Yang GJ, Brook BW, Whelan PI, Cleland S, Bradshaw CJA. Endogenous and exogenous factors controlling temporal abundance patterns of tropical mosquitoes. Ecol Appl. 2008;18:2028-40.

65. Denlinger DL, Armbruster PA. Mosquito diapause. Ann Rev Entomol. 2014 59:73-93.

66. Swellengrebel NL. La dissociation des fonctions sexuelles et nutritives (dissociation gono- trophique) d'Anopheles maculipennis comme cause du paludisme dans les Pays-Bas et ses rapports avec —l'infection domiciliaire. Ann Inst Pasteur. 1929:43:1370-89.

67. Sanburg $L L$, Larsen JR. Effect of photoperiod and temperature on ovarian development in Culex pipiens pipiens. J Insect Physiol. 1973;19:1173-90.

68. Jupp P. Further studies on the overwintering stages of Culex mosquitoes (Diptera: Culicidae) in the highveld region of South Africa. J Entomol Soc S Afr. 1975;38:89-97.

69. Washino RK. The physiological ecology of gonotrophic dissociation and related phenomena in mosquitoes. J Med Entomol. 1977;13:4-5.

70. Benoit J. Water management by dormant insects: comparisons between dehydration resistance during summer aestivation and winter diapause. In: Arturo Navas C, Carvalho JE, editors. Aestivation. Berlin: Springer; 2010. p. 209-29.

71. Russell RC, Whelan PI. Seasonal prevalence of adult mosquitoes at Casuarina and Leanyer. Darwin Aust J Ecol. 1986:11:99-105.

72. Cooling L. On the protracted viability of eggs of Aedes aegypti and $A$. notoscriptus in a desiccated condition in a state of nature. Health. 1924:2:51-2.

73. Graham D. Mosquito life in the Auckland district. Trans Proc R Soc NZ. 1939; 69:210-24.

74. McDonald G, Buchanan $\mathrm{G}$. The mosquito and predatory insect fauna inhabiting fresh water ponds, with particular reference to Culex annulirostris Skuse (Diptera: Culicidae). Aus J Ecol. 1981;6:21-7. 
75. Jansen CC, Zborowski P, Ritchie SA, van den Hurk AF. Efficacy of bird-baited traps placed at different heights for collecting ornithophilic mosquitoes in eastern Queensland. Australia Austral J Entomol. 2009;48:53-9.

76. Kemp J, Lovatt R, Bahr J, Kahler C, Appelman C. Pre-clearing vegetation of the coastal lowlands of the Wet Tropics Bioregion. North Queensland Cunninghamia. 2007;10:285-329.

77. Matthys B, N'Goran EK, Koné M, Koudou BG, Vounatsou P, Cissé G, et al. Urban agricultural land use and characterization of mosquito larval habitats in a medium-sized town of Cote d'Ivoire. J Vector Ecol. 2006;31:319-33.

78. Yasuoka J, Levins R. Impact of deforestation and agricultural development on anopheline ecology and malaria epidemiology. Am J Trop Med Hyg. 2007;76:450-60

79. Olson SH, Gangnon R, Silveira GA, Patz JA. Deforestation and malaria in Mancio Lima county. Brazil Emerg Infect Dis. 2010;16:1108-15.

Submit your next manuscript to BioMed Central and we will help you at every step:

- We accept pre-submission inquiries

- Our selector tool helps you to find the most relevant journal

- We provide round the clock customer support

- Convenient online submission

- Thorough peer review

- Inclusion in PubMed and all major indexing services

- Maximum visibility for your research

Submit your manuscript at www.biomedcentral.com/submit
Biomed Central 